\title{
Subcutaneous ofatumumab in patients with relapsing-remitting multiple sclerosis
}

\section{The MIRROR study}

Amit Bar-Or, MD, Richard A. Grove, MSc, Daren J. Austin, PhD, Jerry M. Tolson, PhD, Susan A. VanMeter, MD, Eric W. Lewis, MD, Frederick J. Derosier, DO, Monica C. Lopez, Sarah T. Kavanagh, MPH, Aaron E. Miller, MD, and Per S. Sorensen, MD

Neurology ${ }^{\circledR}$ 2018;90:e1805-e1814. doi:10.1212/WNL.0000000000005516

\section{Abstract}

\section{Objective}

To assess dose-response effects of the anti-CD20 monoclonal antibody ofatumumab on efficacy and safety outcomes in a phase $2 \mathrm{~b}$ double-blind study of relapsing forms of multiple sclerosis (RMS).

\section{Methods}

Patients $(\mathrm{n}=232)$ were randomized to ofatumumab 3, 30, or $60 \mathrm{mg}$ every 12 weeks, ofatumumab $60 \mathrm{mg}$ every 4 weeks, or placebo for a 24-week treatment period, with a primary endpoint of cumulative number of new gadolinium-enhancing lesions (per brain MRI) at week 12. Relapses and safety/tolerability were assessed, and CD19+ peripheral blood B-lymphocyte counts measured. Safety monitoring continued weeks 24 to 48 with subsequent individualized follow-up evaluating B-cell repletion.

\section{Results}

The cumulative number of new lesions was reduced by $65 \%$ for all ofatumumab dose groups vs placebo $(p<0.001)$. Post hoc analysis (excluding weeks $1-4$ ) estimated a $\geq 90 \%$ lesion reduction vs placebo (week 12 ) for all cumulative ofatumumab doses $\geq 30 \mathrm{mg} / 12 \mathrm{wk}$. Dosedependent CD19 B-cell depletion was observed. Notably, complete depletion was not necessary for a robust treatment effect. The most common adverse event was injection-related reactions ( $52 \%$ ofatumumab, $15 \%$ placebo), mild to moderate severity in $97 \%$, most commonly associated with the first dose and diminishing on subsequent dosing.

\section{Conclusion}

Imaging showed that all subcutaneous ofatumumab doses demonstrated efficacy (most robust: cumulative doses $\geq 30 \mathrm{mg} / 12 \mathrm{wk}$ ), with a safety profile consistent with existing ofatumumab data. This treatment effect also occurred with dosage regimens that only partially depleted circulating B cells.

\section{Classification of evidence}

This study provides Class I evidence that for patients with RMS, ofatumumab decreases the number of new MRI gadolinium-enhancing lesions 12 weeks after treatment initiation.

\author{
Correspondence \\ Dr. Bar-Or \\ amitbar@upenn.edu
}

\section{MORE ONLINE}

$\rightarrow$ Class of Evidence

Criteria for rating

therapeutic and diagnostic

studies

NPub.org/coe 


\section{Glossary}

$\mathbf{A E}=$ adverse event $; \mathbf{C I}=$ confidence interval; $\mathbf{D M T}=$ disease-modifying therapy; EDSS = Expanded Disability Status Scale; FU = follow-up; GdE = gadolinium-enhancing; HAHA = human anti-human antibody; IFU = individualized follow-up; IRR = injection-related reaction; LLN = lower limit of normal; $\mathbf{m A b}=$ monoclonal antibodies; MFIS = Modified Fatigue Impact Scale; MIRROR = Ofatumumab Subcutaneous Administration in Subjects With Relapsing-Remitting Multiple Sclerosis; mITT = modified intent-to-treat; MSFC = Multiple Sclerosis Functional Composite; RA = rheumatoid arthritis; RMS = relapsing multiple sclerosis; RRMS = relapsing-remitting multiple sclerosis; SAE = serious adverse event.

Selectively targeting B cells with anti-CD20 monoclonal antibodies (mAbs), initially shown with genetically engineered chimeric rituximab ${ }^{1,2}$ and subsequently with the humanized ocrelizumab, ${ }^{3,4}$ has proved highly effective at limiting disease activity in patients with relapsing forms of multiple sclerosis (RMS). These studies used intravenous dosing that essentially depletes circulating B cells and substantially reduces the development of new brain lesion activity based on MRI. ${ }^{3,4}$ However, whether efficacy could be obtained with incomplete peripheral B-cell depletion is of considerable interest, especially considering longer-term treatment in patients with chronic disease. The current study used a range of subcutaneous dose regimens of the human anti-CD20 mAb ofatumumab to identify the minimally effective dose for the treatment of RMS.

Ofatumumab binds to a small-loop epitope of CD20 close to the cell surface, inducing efficient complement-dependent cytotoxicity and antibody-dependent cell-mediated cytotoxicity, even when CD20 expression is low. ${ }^{5,6}$ Intravenous ofatumumab is approved for the treatment of chronic lymphocytic leukemia. A small phase 2 dose-escalation study indicated that intravenous ofatumumab at B-cell-depleting doses $(100,300$, and $700 \mathrm{mg})$ resulted in a robust $(\approx 99 \%)$ reduction in new MRI lesion activity in patients with RMS. ${ }^{7}$ Development of subcutaneous ofatumumab anti-CD20 therapy could simplify administration and has been demonstrated to be well tolerated when used in a small rheumatoid arthritis (RA) study. ${ }^{8}$

The aim of this study (Ofatumumab Subcutaneous Administration in Subjects With Relapsing-Remitting Multiple Sclerosis [MIRROR]) was to determine whether a range of doses of subcutaneous ofatumumab reduced new brain lesion development in patients with RMS and whether dose-dependent B-cell depletion and repletion kinetics could be demonstrated with anti-CD20 antibody therapy.

\section{Methods}

\section{Patients}

Eligibility criteria are detailed in the e-supplement, links.lww. com/WNL/A437. Briefly, the trial enrolled patients 18 to 55 years of age with active RMS and an Expanded Disability Status Scale (EDSS) score of 0 to 5.5. Key exclusions were prior use of experimental agents, mAbs (except natalizumab), or immunosuppressive agents. Prior use of other diseasemodifying therapies (DMTs) was allowed.

\section{Standard protocol approvals, registrations, and patient consents}

The study protocol (clinicaltrials.gov NCT01457924; gskclinicalstudyregister.com OMS112831) was approved by all central and local ethics committees. All patients provided written informed consent.

\section{Study design, randomization, and blinding}

This was a phase $2 b$, multicenter, randomized, double-blind, placebo-controlled study with 4 phases: screening, 24-week treatment, 24-week follow-up (FU), and individualized FU (IFU) (figure 1). During the first 12 weeks of the treatment phase, eligible patients were randomized (2:1:1:1:2) to placebo or ofatumumab 3-, 30-, or 60-mg doses every 12 weeks or $60 \mathrm{mg}$ every 4 weeks, respectively (dose selection was based on results of an RA single subcutaneous dose study). ${ }^{8}$ The 12 week placebo-controlled period was considered sufficient to estimate efficacy and dose response of ofatumumab relative to placebo while balancing ethics concerns over prolonged placebo exposure. At week 12, all patients in the placebo group received a single $3-\mathrm{mg}$ ofatumumab dose. The treatment schedule of all groups originally randomized to receive ofatumumab was maintained weeks 12 to 24 .

To evaluate whether tolerability to the higher ofatumumab doses could be enhanced by administration of an initial, smaller dose of ofatumumab (which may provide more gradual lysis of $\mathrm{B}$ cells and reduce cytokine release reactions), 1 week before their first treatment dose (week 0 ), patients in the ofatumumab 30 and $60 \mathrm{mg}$ groups were randomized (1:1 ratio) to receive either placebo or a conditioning dose of ofatumumab (3 mg).

Acetaminophen and an antihistamine (cetirizine or equivalent) were administered orally up to 2 hours before each injection. Randomization was computer generated. Patients were administered either placebo or the designated dose of ofatumumab (1.0-mL volume each) by trained site personnel at weeks $0,1,4,8,12,16$, and 20 to help maintain blinding of patients, neurologists, and study staff. After completion of the treatment phase, the 24-week FU phase monitored patient safety and B-cell repletion. From week 48, individual patients whose CD19+ B-lymphocyte counts remained below the lower limit of normal (LLN) and who did not start a DMT entered the IFU phase to assess B-cell repletion. 


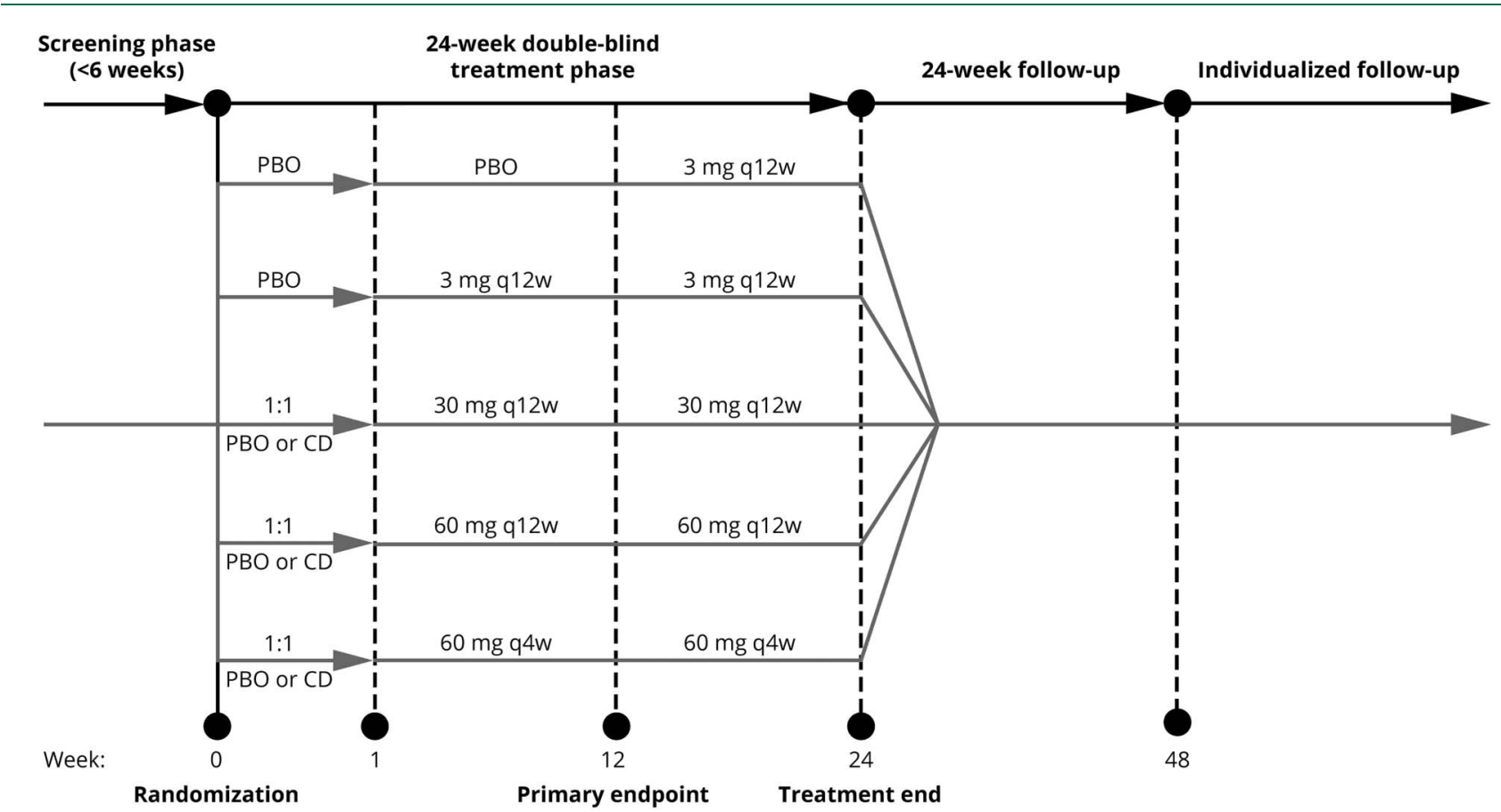

Screening was performed up to 6 weeks before randomization. After completion (or premature discontinuation) of the 24-week treatment phase, patients entered the 24-week follow-up, which assessed patient safety and B-cell repletion. Thereafter (week 48 onwards), individual patients whose CD19+ B-lymphocyte counts remained below the LLN and who did not start a DMT, entered the IFU period. CD = conditioning dose; PBO = placebo; q4w = every 4 weeks; $q 12 \mathrm{w}=$ every $12 \mathrm{weeks}$.

\section{Study endpoints}

Study endpoints are detailed in the e-supplement, links.lww. $\mathrm{com} / \mathrm{WNL} / \mathrm{A} 437$. The primary efficacy endpoint was defined as the cumulative number of new gadolinium-enhancing ( $\mathrm{GdE}$ ) brain lesions at week 12 (based on T1-weighted MRI scans at weeks 4,8 , and 12). Other MRI endpoints were the cumulative number of new GdE lesions at week 24 and cumulative number and total volume of new and new plus persisting GdE lesions, new and/or newly enlarging T2 lesions, and T1-hypointense lesions at weeks 12 and 24. Double-dose gadolinium $(0.2 \mathrm{mmol} /$ $\mathrm{kg}$ ) contrast was used to enhance detection of MS lesions. ${ }^{9}$ MRI scans were analyzed by a central vendor blinded to patient treatment (Perceptive Informatics, Billerica, MA). Clinical efficacy was assessed as the proportion of patients who were relapse free from weeks 0 to 12 . Other clinical endpoints included the EDSS, Multiple Sclerosis Functional Composite (MSFC), and Modified Fatigue Impact Scale (MFIS) scores.

B-cell depletion and repletion kinetics were assessed by CD19+ peripheral blood B-lymphocyte counts with routine fluorescence-activated cell sorter analysis (lower limit of quantification 5 cells $/ \mu \mathrm{L}$ ). Ofatumumab trough concentrations were assessed with standard enzyme-linked immunosorbent assay (lower limit of quantification $100 \mathrm{ng} / \mathrm{mL}$ ) in all patients at weeks 12 and 24 and in a selected pharmacokinetic subpopulation at 1 , $2,3,4,7,14$, and 21 days after dose $(\mathrm{n}=28)$.

Safety was assessed on the basis of adverse event (AE) reporting, the Columbia Suicidality Severity Rating Scale, vital signs, physical and neurologic examinations, laboratory analyses, and immunogenicity (development of human anti-human antibody [HAHA]) with the Meso Scale electrochemiluminescence.

\section{Statistical analysis}

The primary research question was whether subcutaneous ofatumumab reduces the development of new GdE brain lesions in patients with RMS (Class I evidence). A sample size of 196 patients was estimated from the Sorman et al. ${ }^{10}$ placebo estimates (and scaled for the number of MRIs planned in this study) to provide $90 \%$ power to detect a $63 \%$ reduction between the highest ofatumumab dose group (60 mg every 4 weeks) and placebo and to detect a significant dose response at the 5\% significance level for the primary endpoint based on a generalized linear model with underlying negative binomial distribution (e-supplement, links.lww.com/WNL/A437).

The primary efficacy population was the modified intent-to-treat (mITT) population (all patients randomized to treatment who took $\geq 1$ dose of placebo or ofatumumab and who had $\geq 1$ postscreening MRI assessment). The primary dataset for MRI endpoints was all evaluable scans, including all on-treatment MRI scans for each patient in the mITT population, allowing estimates of lesion rates to be calculated across the entire 12-week treatment phase. All MRI endpoint analyses were cumulative counts (intermediate time points were not analyzed separately) and based on preplanned screening MRI stratification for either no GdE lesions or $\geq 1 \mathrm{GdE}$ lesions. To account for protocol violations, a per-protocol population was also considered in 
the efficacy analyses (e-supplement, links.lww.com/WNL/ A437). For clinical efficacy assessing relapses, the proportion of patients relapsing in each ofatumumab dose group was compared with placebo by the Fisher exact test.

B-cell depletion and repletion were summarized as actual counts and change from baseline counts of CD19+ B lymphocytes. Additional post hoc analyses were conducted with a generalized linear model with negative binomial regression of new lesions used as a linear function of weighted mean CD19+ B cells.

Safety analyses (descriptive statistics) were conducted on the safety population, comprising all patients randomized and receiving study medication. MSFC and MFIS scores were analyzed with an analysis of covariance model adjusting for baseline score and stratum. Safety endpoints were monitored to the end of IFU. Time to B-cell repletion from the last ofatumumab dose to the LLN or baseline (if less than the LLN) was estimated with Kaplan-Meier methods.

\section{Data availability}

The results summary for this study (NCT01457924/ OMS112831) is available on clinicaltrials.gov, the default register for GlaxoSmithKline Human Subject Research. If the study does not meet the criteria for posting to clinicaltrials.gov, the study will be available on the GlaxoSmithKline Clinical Study Register at gsk-clinicalstudyregister.com. For interventional studies that evaluate our medicines, anonymized patient-level data will be made available to independent researchers, subject to review by an independent panel, at clinicalstudydatarequest. com within 6 months of publication. To protect the privacy of patients and individuals involved in our studies, GlaxoSmithKline does not publicly disclose patient-level data.

\section{Results}

\section{Patient disposition}

In total, 232 patients were randomized, with 231 receiving $\geq 1$ doses of study drug (analyzed as the safety population) (figure e-1). Of these, 219 (95\%) patients completed treatment through week 12, with 214 completing through week 12 to 24 . Three of the 231 patients did not have a postbaseline MRI, leaving 228 analyzed for efficacy as the mITT population. At week 24, 221 (96\%) patients entered the FU phase, including 7 of 17 patients who withdrew from treatment. A total of 212 (92\%) patients completed to week 48 . Of the 112 patients entering the IFU phase, 88 completed this phase (e-supplement, links.lww.com/WNL/A437). Baseline characteristics of the safety and mITT populations were generally balanced across treatment groups (table 1).

\section{Efficacy}

\section{MRI endpoints}

The primary outcome analysis (mITT population) demonstrated a statistically significant $65 \%$ reduction in the mean rate of cumulative new GdE lesions for all ofatumumab groups vs placebo between weeks 0 and 12 (rate ratio 0.35 , 95\% confidence interval $[\mathrm{CI}] 0.221-0.548, p<0.001)$ (figure $2 \mathrm{~A}$ and table 2 ). This effect was evident as early as week 4, when the same results are depicted as the mean number of new GdE lesions counted at the same time points (figure 2B). In post hoc analysis, which more closely reflects the approach used in prior studies ${ }^{2,3}$ (e-supplement, links. lww.com/WNL/A437), the reduction in the mean rate of cumulative new GdE lesions from weeks 4 to 12 ranged from $71 \%(0.29$ [95\% CI $0.133-0.643])$ to $92 \%(0.08$ [95\% CI $0.044-0.162])$ across ofatumumab groups vs placebo $(p \leq$ 0.002 ), with $\geq 90 \%$ suppression of new lesions at all cumulative doses $\geq 30 \mathrm{mg}$ over 12 weeks (0.08 [95\% CI $0.044-0.162]$ to 0.10 [95\% CI $0.056-0.187]$ ) (table 2 and figure e-2, links.lww.com/WNL/A435). All secondary MRI endpoints, including the cumulative number of $\mathrm{T} 2$ lesions (figure e-3, links.lww.com/WNL/A435), as well as all analyses in the per-protocol population, supported the primary analysis (tables e-1 and e-2, links.lww.com/WNL/A436).

\section{Clinical endpoints}

Overall, 26 patients relapsed during the first 12 weeks; 11 (42\%) relapsed during the first 4 weeks (table e-3, links.lww. com/WNL/A436). Although more relapses occurred in the placebo group, the proportion of patients relapsing during the first 4 weeks ( $6 \%-13 \%$ across the ofatumumab groups vs $13 \%$ placebo) did not differ statistically $(p \geq 0.488)$. Over the 24week period, 17 (25\%) patients relapsed in the placebo group vs 3 to 10 patients $(9 \%-22 \%)$ across the ofatumumab groups. The proportion of relapses remained low throughout the 24week FU phase across all dose groups $(6 \%-15 \%)$. There were no significant differences between ofatumumab and placebo in MSFC and MFIS scores. Most patients (79\%) had unchanged EDSS scores at weeks 12 and 24 with no notable differences between groups.

\section{Pharmacodynamics}

A dose-dependent depletion of B cells was observed, with greater depletion for the 60 -mg dose every 4 weeks (to $<2 \%$ of baseline levels at maximum depletion) and the 30 - and 60-mg dose every 12 weeks (to $\approx 5 \%$ of baseline) than for the 3 -mg dose every 12 weeks (to $\approx 25 \%$ of baseline) (figure $2 \mathrm{C}$ ). While all dose groups appeared to exhibit similar rates of B-cell repopulation, time to onset of repopulation appeared longer for the higher-dose groups. By study end, B-cell repletion was achieved by $64 \%$ to $74 \%$ of patients across ofatumumab groups (table e-4, links.lww.com/WNL/A436). Post hoc analyses indicated a statistically significant relationship between weighted mean B-cell count and new GdE lesions (slope 0.63 , 95\% CI 0.41-0.85, $p<0.001$ ) (figure e-4, links. lww.com/WNL/A435).

\section{Safety}

In total, $43(64 \%)$ patients receiving placebo and 121 (74\%) receiving ofatumumab (65\%-81\% across dose groups) experienced AEs during weeks 0 to 12 . During weeks 12 to 24 and 24 to 48 , the proportions of patients who experienced AEs across 
Table 1 Baseline patient demographic characteristics (safety population) and disease history (mITT population)

\begin{tabular}{|c|c|c|c|c|c|c|}
\hline Parameter & $\begin{array}{l}\text { Placebo }^{a} \\
(n=67)\end{array}$ & $\begin{array}{l}\text { Ofatumumab } \\
3 \mathrm{mg} \text { every } \\
12 \mathrm{wk}(\mathrm{n}=34)\end{array}$ & $\begin{array}{l}\text { Ofatumumab } \\
30 \mathrm{mg} \text { every } \\
12 \mathrm{wk}(\mathrm{n}=32)\end{array}$ & $\begin{array}{l}\text { Ofatumumab } \\
60 \mathrm{mg} \text { every } \\
12 \mathrm{wk}(\mathrm{n}=34)\end{array}$ & $\begin{array}{l}\text { Ofatumumab } \\
60 \mathrm{mg} \text { every } \\
4 \mathrm{wk}(\mathrm{n}=64)\end{array}$ & $\begin{array}{l}\text { Total } \\
(n=231)\end{array}$ \\
\hline Demographics (safety population), n & 67 & 34 & 32 & 34 & 64 & 231 \\
\hline Sex, female, n (\%) & $46(69)$ & $22(65)$ & $24(75)$ & $22(65)$ & $41(64)$ & $155(67)$ \\
\hline Race, white, n (\%) & $65(97)$ & $34(100)$ & $31(97)$ & $34(100)$ & $61(95)$ & 225 (97) \\
\hline Age, mean (SD), y & $37.7(9.38)$ & $38 \cdot 1(8.29)$ & $37.2(10.04)$ & $37.3(9.67)$ & $36.2(9.57)$ & $37.2(9.36)$ \\
\hline Body mass index, mean (SD), kg/m² & $26.4(6.86)$ & $24.6(3.42)$ & $24.9(3.77)$ & $25.8(4.31)$ & $26.0(5.85)$ & $25.7(5.43)$ \\
\hline Disease history (mITT population), n & 67 & 33 & 32 & 33 & 63 & 228 \\
\hline Clinical disease duration, mean (SD), y & $3.92(5.293)$ & $3.90(6.193)$ & $6.10(6.032)$ & $3.59(4.407)$ & $4.68(5.641)$ & $4.38(5.530)$ \\
\hline Relapses (last 12 mo), mean (SD), n & $1.3(0.58)$ & $1.4(0.61)$ & $1.3(0.67)^{\mathrm{b}}$ & $1.3(0.60)$ & $1.3(0.70)$ & $1.3(0.3)$ \\
\hline Relapses (last 24 mo), mean (SD), n & $1.8(0.78)$ & $1.7(0.91)$ & $1.9(1.12)^{b}$ & $1.9(0.86)$ & $1.8(0.85)$ & $1.8(0.88)$ \\
\hline Time since last relapse, mean (SD), d & $\begin{array}{l}150.3 \\
(102.25)\end{array}$ & $128.9(78.38)$ & $184.7(126.71)$ & $165.5(111.71)$ & $139.8(117.65)$ & $\begin{array}{l}151.3 \\
(109.25)\end{array}$ \\
\hline $\begin{array}{l}\text { MRI scan with active lesions (last } 12 \mathrm{mo} \text { ), } \\
\text { n (\%) }\end{array}$ & $29(43)$ & $15(45)$ & $11(34)$ & $15(45)$ & $28(44)$ & 98 (43) \\
\hline
\end{tabular}

Abbreviation: $\mathrm{mITT}=$ modified intent-to-treat.

a Patients randomized to the placebo group received $3 \mathrm{mg}$ ofatumumab at week 12 .

${ }^{\mathrm{b}} \mathrm{n}=31$.

treatment groups were $45 \%$ to $62 \%$ and $47 \%$ to $55 \%$, respectively (table 3 ). AEs were largely mild to moderate in severity, and no patients died. Incidences of serious AEs (SAEs) were $3 \%,<1 \%, 4 \%$, and $<1 \%$ in weeks 0 to 12,12 to 24 , and 24 to 48 and the IFU phase, respectively. The only SAEs to occur in $\geq 1$ patient during the treatment phase were injection-related reactions (IRRs), occurring in 3 patients; all continued in the study, including 1 patient who reportedly experienced a cytokine-release syndrome within hours of the first ofatumumab $(60 \mathrm{mg})$ dose. Other SAEs occurring in single patients were cholelithiasis and hypokalemia (both with $60 \mathrm{mg}$ ofatumumab every 4 weeks) and angioedema and urticaria (both in the same patient receiving $3 \mathrm{mg}$ ofatumumab). There was no pattern of SAEs in the 24-week FU phase. During the IFU, 2 (2\%) patients, both in the ofatumumab $60 \mathrm{mg}$ every 4 weeks group, reported a total of 2 SAEs: head injury and malignant melanoma stage IV. The latter was considered treatment related, and the patient recovered (as noted by the investigator).

The incidence of AEs was highest in the ofatumumab $60 \mathrm{mg}$ every 4 weeks group during weeks 0 to 12 of treatment (81\%) and was lowest in this group during weeks 12 to 24 (45\%). The most common week 0 to 12 AEs in the ofatumumab groups were IRRs (41\%-66\% vs $15 \%$ for placebo, table e-5, links.lww.com/WNL/A436, and figure e-5, links.lww.com/ WNL/A435). Their incidence was similar for each regimen regardless of preconditioning dose (table e-6, links.lww.com/ WNL/A436). Most IRRs were of mild to moderate severity, resolved the same or following day, and were associated primarily with the first ofatumumab dose (29\%-50\%); their incidence diminished with subsequent ofatumumab dosing (1\%-18\% at week 12$)$.

Overall rates of any infection-related AEs were similar across treatment groups (table e-5, links.lww.com/WNL/A436), with no cases of opportunistic infections (including progressive multifocal leukoencephalopathy) or hepatitis B reactivation. There were no clinically meaningful changes in mood, vital signs, or laboratory parameters, including cytopenias. Four patients ( 3 at $3 \mathrm{mg}$ and 1 at $30 \mathrm{mg}$ ofatumumab) had a single positive result for HAHAs during the treatment phase (all titers $\leq 32$ ), and 1 patient $(3 \mathrm{mg}$ ) also had a positive titer during FU phase week 36 (negative at week 48); B-cell depletion was as expected in all.

No new or unexpected safety findings occurred in either the week 24 to $48 \mathrm{FU}$ or IFU periods. AEs leading to withdrawal were reported in $\leq 2 \%$ of patients in each phase. In total, 8 patients discontinued because of AEs, mostly IRRs (2 patients) and decreased immunoglobulin G (2 patients). Further pharmacokinetic results are presented in figure e-6, links.lww.com/WNL/A435.

\section{Discussion}

This phase $2 \mathrm{~b}$ study of subcutaneously administered ofatumumab used a wide range of doses to explore a minimally effective dose as a potential treatment for relapsing-remitting MS (RRMS). In the primary (week 0-12) efficacy analysis, 

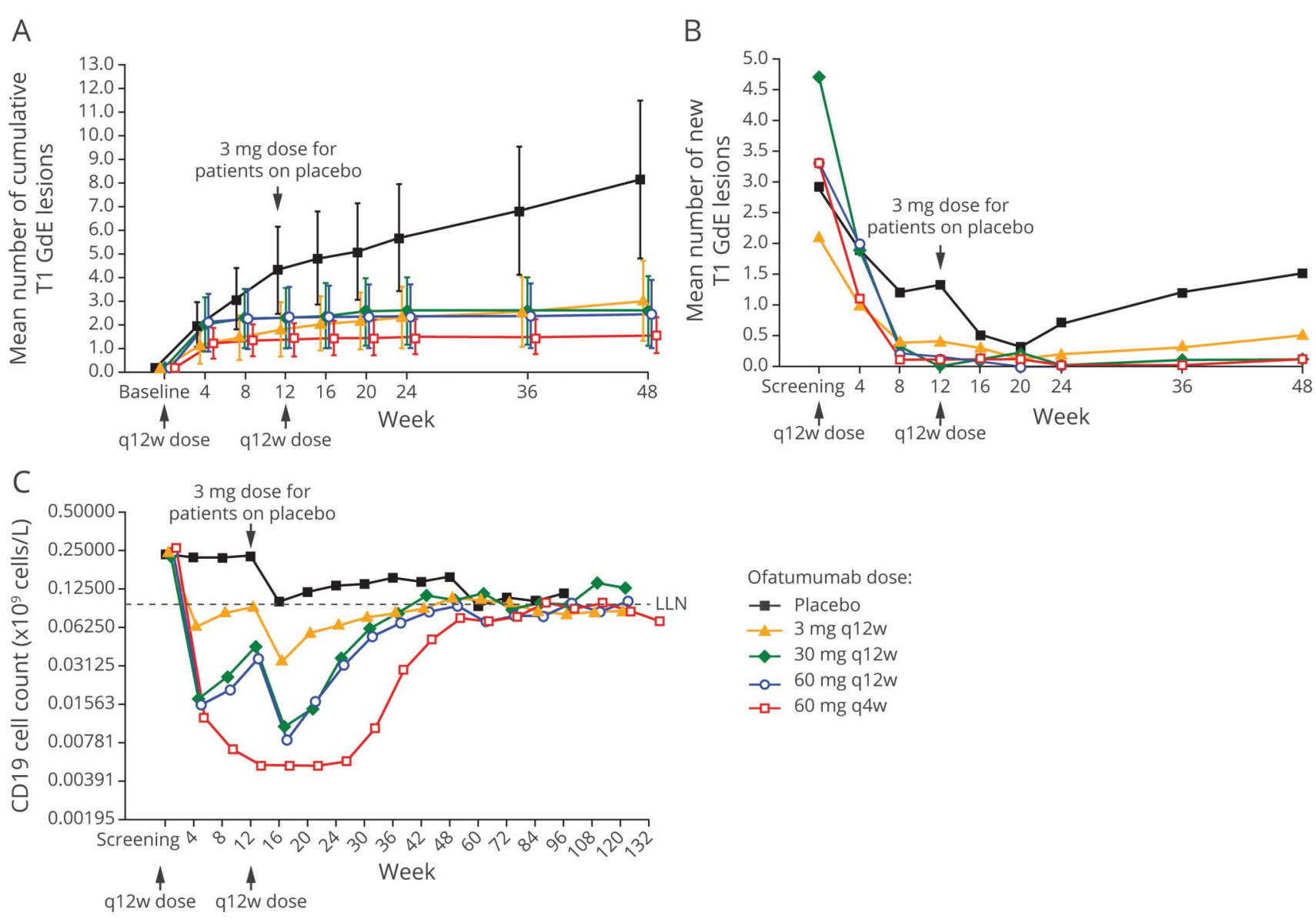

(A) Primary efficacy outcome measure: mean ( $95 \%$ confidence interval) cumulative number of GdE T1 lesions over time (all evaluable scans dataset). (B) New lesion evolution (post hoc): mean number of new GdE T1 lesions at different MRI time points. From week 8 through 24 , the appearance of new GdE T1 lesions was very low at doses of $\geq 30$ mg every 12 weeks. (C) Pharmacodynamic response showing dose-response depletion of CD19 B cells and repletion kinetics (safety population). The median time to repletion based on Kaplan-Meier estimates was $\approx 11$ months for the of atumumab 3 and 30 mg every 12 weeks groups and $\approx 14$ months for the ofatumumab 60 mg every 12 and 4 weeks groups. (A) Faster repletion time (of $\approx 6$ months) was noted for the placebo group, who received a single ofatumumab $3 \mathrm{mg}$ dose at week 12 (and in whom $32 \%$ did not deplete). Of those patients whose $B$ cells had repleted by the end of the study, the time to repletion appeared to generally be longer in the 60-mg ofatumumab dose groups compared with the other ofatumumab dose groups. There were no signs of B-cell repletion during the 4-week interdosing interval with the every 4 weeks regimen. Some B-cell repletion was seem. GdE = gadoliniumenhancing; LLN = lower limit of normal; q4w = every 4 weeks; q12w = every 12 weeks.

ofatumumab treatment across dosing regimens significantly reduced new GdE lesions by $65 \%$ vs placebo. Early MRI time points are often excluded in a priori efficacy analyses ${ }^{2,3,7}$ because disease activity initiated before the onset of action of therapy could potentially dilute actual treatment effect. In keeping with this, post hoc analysis excluding week 0 to $4 \mathrm{MRI}$ data revealed an even greater $(\geq 90 \%)$ reduction of new $\mathrm{GdE}$ lesions vs placebo for ofatumumab at all doses $\geq 30 \mathrm{mg}$ every 12 weeks. Similar patterns were seen with multiple secondary imaging outcome measures and with the number of patients relapsing (weeks 4-12 less than weeks 0-4). Week 4 was used as the baseline in post hoc analyses regardless of whether a conditioning dose of $3 \mathrm{mg}$ ofatumumab was administered. While it is possible that the conditioning dose may have confounded the data, this study focused on the steady-state outcome, and we do not believe the conditioning dose would have had a significant effect on efficacy in the context of the overall exposure to the higher doses at steady state.
Currently approved anti-CD20 treatment generally results in complete/near-complete depletion of circulating B cells, although it is not clear that this is necessary to achieve a high level of efficacy. ${ }^{4}$ Here, ofatumumab treatment resulted in rapid dose-dependent B-cell depletion, which correlated with efficacy outcomes. A cumulative dose of $60 \mathrm{mg}$ ofatumumab administered over 12 weeks provided maximal benefit, with no additional suppression of lesions at higher cumulative doses. Distinct from other studies of B-cell depletion in RRMS, ofatumumab dosage regimens that did not completely deplete circulating B cells could achieve robust treatment effects. Indeed, while the ofatumumab 3-mg dose every 12 weeks reduced circulating B-cell levels to $\approx 25 \%$ of baseline (clearly less than the $5 \%$ of baseline achieved with 30 - and 60mg dose every 12 weeks), it was surprisingly effective in significantly reducing new $\mathrm{T} 1 \mathrm{GdE}$ lesions, with a $71 \%$ reduction in mean rate of cumulative new GdE lesions from weeks 4 to 12. On the basis of post hoc analyses, $\geq 90 \%$ suppression of 


\begin{tabular}{|c|c|c|c|c|c|c|c|}
\hline Endpoint & Statistic & Population & Placebo $^{a}$ & $\begin{array}{l}\text { Ofatumumab } 3 \mathrm{mg} \\
\text { every } 12 \mathrm{wk}\end{array}$ & $\begin{array}{l}\text { Ofatumumab } 30 \mathrm{mg} \\
\text { every } 12 \mathrm{wk}\end{array}$ & $\begin{array}{l}\text { Ofatumumab } 60 \mathrm{mg} \\
\text { every } 12 \mathrm{wk}\end{array}$ & $\begin{array}{l}\text { Ofatumumab } 60 \mathrm{mg} \\
\text { every } 4 \mathrm{wk}\end{array}$ \\
\hline \multicolumn{8}{|l|}{$\begin{array}{l}\text { Cumulative No. of new GdE T1 lesions } \\
\text { at weeks } 12 \text { and } 24\end{array}$} \\
\hline & No. & $\mathrm{mITT}$ & 67 & 33 & 30 & 33 & 63 \\
\hline \multirow[t]{2}{*}{ Weeks $0-12^{b}$} & Mean rate ${ }^{d}$ & $\mathrm{mlTT}$ & 0.99 & 0.35 & 0.35 & 0.35 & 0.35 \\
\hline & Rate ratio $(95 \% \mathrm{Cl})$ & $\mathrm{mlTT}$ & - & $0.35(0.221-0.548)^{\mathrm{e}}$ & $0.35(0.221-0.548)^{\mathrm{e}}$ & $0.35(0.221-0.548)^{\mathrm{e}}$ & $0.35(0.221-0.548)^{\mathrm{e}}$ \\
\hline \multirow[t]{2}{*}{ Weeks $4-12^{b}$ (post hoc analysis) } & Mean rate ${ }^{d}$ & $\mathrm{mlTT}$ & 0.84 & 0.25 & 0.09 & 0.08 & 0.07 \\
\hline & Rate ratio $(95 \% \mathrm{Cl})$ & $\mathrm{mITT}$ & - & $0.29(0.133-0.643)^{f}$ & $0.10(0.056-0.187)^{\mathrm{e}}$ & $0.09(0.049-0.170)^{\mathrm{e}}$ & $0.08(0.044-0.162)^{\mathrm{e}}$ \\
\hline \multirow[t]{2}{*}{ Week 0-24c } & Mean rate ${ }^{d}$ & $\mathrm{mITT}$ & 0.67 & 0.25 & 0.25 & 0.23 & 0.15 \\
\hline & Rate ratio $(95 \% \mathrm{Cl})$ & $\mathrm{mlTT}$ & & $0.38(0.20-0.72)^{g}$ & $0.38(0.20-0.72)^{g}$ & $0.35(0.19-0.65)^{\mathrm{e}}$ & $0.23(0.13-0.39)^{\mathrm{e}}$ \\
\hline \multicolumn{8}{|l|}{$\begin{array}{l}\text { Cumulative No. of new/enlarging } \\
\text { total T2 lesions at week } 12\end{array}$} \\
\hline & No. & $\mathrm{mITT}$ & 67 & 32 & 30 & 33 & 63 \\
\hline \multirow[t]{2}{*}{ Weeks $0-12^{b}$} & Mean rate ${ }^{d}$ & $\mathrm{mlTT}$ & 1.04 & 0.42 & 0.37 & 0.42 & 0.30 \\
\hline & Rate ratio $(95 \% \mathrm{Cl})$ & $\mathrm{mlTT}$ & 1.00 & $0.40(0.21-0.77)^{g}$ & $0.36(0.18-0.69)^{f}$ & $0.40(0.21-0.76)^{g}$ & $0.28(0.16-0.49)^{\mathrm{e}}$ \\
\hline \multirow[t]{2}{*}{ Weeks $4-12^{b}$ (post hoc analysis) } & Mean rate ${ }^{d}$ & $\mathrm{mlTT}$ & 0.83 & 0.36 & 0.11 & 0.09 & 0.08 \\
\hline & Rate ratio $(95 \% \mathrm{Cl})$ & $\mathrm{mITT}$ & 1.00 & $0.43(0.20-0.90)^{\mathrm{h}}$ & $0.13(0.05-0.35)^{\mathrm{e}}$ & $0.10(0.04-0.27)^{\mathrm{e}}$ & $0.10(0.04-0.21)^{\mathrm{e}}$ \\
\hline \multicolumn{8}{|l|}{$\begin{array}{l}\text { Cumulative No. of total } \\
\text { (new/persisting) GdE T1 lesions } \\
\text { at week 12 }\end{array}$} \\
\hline & No. & $\mathrm{mITT}$ & 67 & 32 & 30 & 33 & 62 \\
\hline \multirow[t]{2}{*}{ Weeks $0-12^{c}$} & Mean rate ${ }^{d}$ & $\mathrm{mlTT}$ & 1.43 & 0.45 & 0.80 & 0.73 & 0.46 \\
\hline & Rate ratio $(95 \% \mathrm{Cl})$ & $\mathrm{mlTT}$ & & $0.31(0.16-0.60)^{\mathrm{e}}$ & $0.56(0.29-1.06)$ & $0.51(0.27-0.95)^{h}$ & $0.32(0.19-0.55)^{e}$ \\
\hline \multirow[t]{2}{*}{ Weeks 4-12 (post hoc analyses) ${ }^{\mathrm{c}}$} & Mean rate ${ }^{d}$ & $\mathrm{mlTT}$ & 1.35 & 0.37 & 0.47 & 0.43 & 0.31 \\
\hline & Rate ratio $(95 \% \mathrm{Cl})$ & $\mathrm{mlTT}$ & & $0.27(0.13-0.57)^{e}$ & $0.35(0.17-0.75)^{\mathrm{e}}$ & $0.32(0.15-0.67)^{f}$ & $0.23(0.12-0.42)^{\mathrm{e}}$ \\
\hline \multicolumn{8}{|l|}{$\begin{array}{l}\text { Cumulative No. of new/enlarging } \\
\text { total T2 lesions at week } 24\end{array}$} \\
\hline & No. & $\mathrm{mlTT}$ & 67 & 33 & 30 & 33 & 63 \\
\hline & & & & & & & Continued \\
\hline
\end{tabular}


GdE MRI lesion activity appeared to be achievable in this study when B cells were depleted to a level of $\approx 32$ cells $/ \mu \mathrm{L}$ (although the meaning and utility of such a measure require further study). B-cell repletion between dosing was seen with the less frequent administration of ofatumumab (i.e., every 12 weeks) but not with the more frequent dosing (i.e., every 4 weeks), and the time to repletion was longer for the higher-dose groups. Repletion in all ofatumumab doses occurred faster than previously reported with anti-CD20 therapy. ${ }^{4,11} \mathrm{~A}$ dose response in the kinetics of depletion-repletion suggested that higher-dose/ higher-frequency regimens result in greater depth of B-cell depletion in tissues. This insight from patients is consistent with anti-CD20 animal studies in which higher doses led to greater depth of B-cell depletion in different lymphoid tissues. ${ }^{12,13}$ Indeed, the kinetics of repletion may be more informative than the degree of initial depletion, especially with regimens that result in near-complete depletion, where the nadir of circulating B cells becomes an insensitive measure of both the depth of initial B-cell depletion and the onset of repletion.

Prior ofatumumab exposure (in oncology, MS, and other autoimmune disorders) ${ }^{7,14-17}$ has largely been intravenous, with the exception of a limited single subcutaneous dose study in RA. ${ }^{8}$ We report overall good tolerability and no new/unexpected safety findings with subcutaneous ofatumumab. As expected, IRRs were the most common AEs; most were associated with the first dose of ofatumumab and resolved within 1 day of onset. We found no benefit of adding a $(3 \mathrm{mg})$ conditioning dose. Subcutaneous injection may have greater practicality compared with intravenous administration requiring repeat access to health care providers or infusion facilities. For some patients, more control over the exact timing and circumstance of administration would also be an advantage. As a fully human (compared with chimeric or humanized ${ }^{18}$ ) antibody, ofatumumab would be expected to exhibit very low immunogenicity, and indeed, no HAHAs were reported in the ofatumumab intravenous study in MS. ${ }^{7}$ In the current study, very low-titer HAHAs were reported in 4 patients. Further investigation into the incidence of HAHAs with ofatumumab is warranted.

Overall, this study demonstrates that ofatumumab has a high capacity to suppress new brain MRI lesions with subcutaneous administration at considerably lower (and incompletely B-cell depleting) doses compared with those previously studied in patients with MS. The $\geq 90 \%$ suppression of new T1 GdE and T2 lesions with ofatumumab is consistent with the effects demonstrated by other anti-CD20 mAbs at doses resulting in maximal peripheral B-cell depletion. ${ }^{2-4}$ The prospect of an efficacious subcutaneous B-cell-targeting therapy raises the possibility of self-administration and therefore improvement over intravenous administration in terms of both convenience of use and the use of health care resources. It remains to be seen whether the less profound depletion and faster repletion of B cells achieved with ofatumumab will also translate into a more favorable safety profile. Our findings thus support investigation of low-dose subcutaneous ofatumumab in longerterm efficacy studies in RRMS. 
Table 3 Overview of AEs of treatment phase and 24-week follow-up phase

\begin{tabular}{|c|c|c|c|c|c|c|}
\hline AE & Placebo $^{a}$ & $\begin{array}{l}\text { Ofatumumab } \\
3 \mathrm{mg} \text { every } \\
12 \mathrm{wk}\end{array}$ & $\begin{array}{l}\text { Ofatumumab } \\
30 \mathrm{mg} \text { every } \\
12 \mathrm{wk}\end{array}$ & $\begin{array}{l}\text { Ofatumumab } \\
60 \mathrm{mg} \text { every } \\
12 \mathrm{wk}\end{array}$ & $\begin{array}{l}\text { Ofatumumab } \\
60 \mathrm{mg} \text { every } \\
4 \mathrm{wk}\end{array}$ & $\begin{array}{l}\text { Total } \\
\text { ofatumumab }\end{array}$ \\
\hline Weeks $0-12, n$ & 67 & 34 & 32 & 34 & 64 & 164 \\
\hline Any AE, n (\%) & $43(64)$ & $24(71)$ & $23(72)$ & $22(65)$ & $52(81)$ & $121(74)$ \\
\hline $\begin{array}{l}\text { AE leading to withdrawal } \\
\text { from treatment }\end{array}$ & 0 & $2(6)$ & $1(3)$ & 0 & $1(2)$ & $4(2)$ \\
\hline Treatment-related AEs & $15(22)$ & $17(50)$ & $17(53)$ & $17(50)$ & $44(69)$ & $95(58)$ \\
\hline SAES & 0 & 0 & 0 & $1(3)$ & $4(6)$ & $5(3)$ \\
\hline \multicolumn{7}{|l|}{ Maximum intensity } \\
\hline Mild & $22(33)$ & $13(38)$ & $11(34)$ & $11(32)$ & $29(45)$ & $64(39)$ \\
\hline Moderate & $21(31)$ & $10(29)$ & $11(34)$ & $10(29)$ & $19(30)$ & $50(30)$ \\
\hline Severe & 0 & $1(3)$ & $1(3)$ & $1(3)$ & $4(6)$ & $7(4)$ \\
\hline Weeks 12-24, n & 65 & 31 & 30 & 33 & 60 & 219 \\
\hline Any AE, n (\%) & $40(62)$ & $16(52)$ & $15(50)$ & $20(61)$ & $27(45)$ & $118(54)$ \\
\hline $\begin{array}{l}\text { AE leading to withdrawal } \\
\text { from treatment }\end{array}$ & 0 & $2(6)$ & 0 & 0 & $1(2)$ & $3(1)$ \\
\hline Treatment-related AEs & $17(26)$ & $9(29)$ & $6(20)$ & $9(27)$ & $9(15)$ & $50(23)$ \\
\hline SAES & 0 & $1(3)$ & 0 & 0 & 0 & $1(<1)$ \\
\hline \multicolumn{7}{|l|}{ Maximum intensity } \\
\hline Mild & $20(31)$ & $9(29)$ & $8(27)$ & $10(30)$ & $19(32)$ & $66(30)$ \\
\hline Moderate & $18(280)$ & $7(23)$ & $7(23)$ & $10(30)$ & $8(13)$ & $50(23)$ \\
\hline Severe & $2(3)$ & 0 & 0 & 0 & 0 & $2(<1)$ \\
\hline 24-wk FU Phase, N & 66 & 31 & 32 & 33 & 59 & 220 \\
\hline Any AE, n (\%) & $35(53)$ & $17(55)$ & $15(47)$ & $16(48)$ & $28(47)$ & $111(50)$ \\
\hline $\begin{array}{l}\text { AE leading to withdrawal } \\
\text { from treatment }\end{array}$ & 0 & 0 & $1(3)$ & 0 & 0 & $1(<1)$ \\
\hline Treatment-related AEs & $6(9)$ & $3(10)$ & $4(13)$ & $3(9)$ & $4(7)$ & $20(9)$ \\
\hline Serious AEs & $5(8)$ & $1(3)$ & $1(3)$ & 0 & $2(3)$ & $9(4)$ \\
\hline \multicolumn{7}{|l|}{ Maximum intensity } \\
\hline Mild & $16(24)$ & $8(26)$ & $7(22)$ & $9(27)$ & $16(27)$ & $56(25)$ \\
\hline Moderate & $18(27)$ & $9(29)$ & $7(22)$ & $6(18)$ & $12(20)$ & $52(24)$ \\
\hline Severe & $1(2)$ & 0 & $1(3)$ & $1(3)$ & 0 & $3(1)$ \\
\hline IFU phase, n & 16 & 18 & 16 & 20 & 42 & 112 \\
\hline Serious AEs & 0 & 0 & 0 & 0 & $2(5)$ & $2(2)$ \\
\hline
\end{tabular}

Abbreviations: $\mathrm{AE}$ = adverse event; FU = follow-up; IFU = individualized follow-up; SAE = serious adverse event.

${ }^{a}$ Patients randomized to the placebo group received $3 \mathrm{mg}$ of ofatumumab at week 12 .

\section{Author contributions}

All authors agree to be accountable for all aspects of the work in ensuring that questions related to the accuracy or integrity of any part of the work are appropriately investigated and resolved. Amit Bar-Or, MD, designed the study, was a study investigator, reviewed and interpreted the data, participated in writing the initial manuscript draft, and approved the final version of the manuscript to be published. Richard A. Grove, MSc, designed the study, did statistical analyses, was involved in the conduct of the study, reviewed and interpreted the data, 
participated in writing the initial manuscript draft, and approved the final version of the manuscript to be published. Daren J. Austin, $\mathrm{PhD}$, designed the study, was responsible for pharmacokinetic and pharmacodynamic analyses, reviewed and interpreted the data, participated in writing the initial manuscript draft, and approved the final version of the manuscript to be published. Jerry $\mathrm{M}$. Tolson, $\mathrm{PhD}$, designed the study, was involved in the conduct of the study, reviewed and interpreted the data, participated in writing the initial manuscript draft, and approved the final version of the manuscript to be published. Susan A. VanMeter, MD, and Eric W. Lewis, MD, were involved in the conduct of the study, reviewed and interpreted the data, participated in writing the initial manuscript draft, and approved the final version of the manuscript to be published. Frederick J. Derosier, DO, designed the study, was involved in the conduct of the study, reviewed and interpreted the data, participated in writing the initial manuscript draft, and approved the final version of the manuscript to be published. Monica C. Lopez was involved in the conduct of the study, reviewed and interpreted the data, participated in writing the initial manuscript draft, and approved the final version of the manuscript to be published. Sarah T. Kavanagh, MPH, did statistical analyses, reviewed and interpreted the data, participated in writing the initial manuscript draft, and approved the final version of the manuscript to be published. Aaron E. Miller, $\mathrm{MD}$, served on the Independent Data Monitoring Committee, reviewed and interpreted the data, participated in writing the initial manuscript draft, and approved the final version of the manuscript to be published. Per S. Sorenson, MD, designed the study, was a study investigator, reviewed and interpreted the data, participated in writing the initial manuscript draft, and approved the final version of the manuscript to be published.

\section{Acknowledgment}

The sponsors and authors thank the patients who volunteered to participate in this study and acknowledge Ken Wiesen, $\mathrm{PhD}$, Francesca Balordi, PhD (Medicus International New York), and Joyce Willetts, $\mathrm{PhD}$ (consultant for PharmaWrite), for writing assistance funded by GlaxoSmithKline. The sponsors and authors also thank each of the 52 investigators and their participating sites, as well as the Independent Data Monitoring Committee (Chris Polman, Aaron Miller, Gary Cutter) and Progressive Multifocal Leukoencephalopathy Adjudication Committee (David Clifford, Eugene Major, Avindra Nath).

\section{Study funding}

This study (ClinicalTrials.gov NCT01457924) was sponsored by GlaxoSmithKline (GlaxoSmithKline study number OMS112831). Editorial support in the form of collating author comments, grammatical editing, and submission support was provided by Alex Lowe, PhD, of Fishawack Indicia Ltd, funded by GlaxoSmithKline.

\section{Disclosure}

A. Bar-Or, R. Grove, D. Austin, J. Tolson, S. VanMeter, E. Lewis, F. Derosier, M. Lopez, and S. Kavanagh were employees of/ stockholders in GlaxoSmithKline at the time of this study. A. Miller has served as a consultant or a member of the scientific advisory board for GlaxoSmithKline. P. Sorenson has served on scientific advisory boards for Genmab (a codeveloper of ofatumumab) and GlaxoSmithKline; has served on steering committees or independent data monitoring boards in clinical trials sponsored by Genmab and GlaxoSmithKline and has received funding of travel for these activities; and has served as editor-in-chief of the European Journal of Neurology. Go to Neurology.org/ $\mathrm{N}$ for full disclosures.

Received July 11, 2017. Accepted in final form February 23, 2018.

\section{References}

1. Bar-Or A, Calabresi PA, Arnold D, et al. Rituximab in relapsing-remitting multiple sclerosis: a 72 -week, open-label, phase I trial. Ann Neurol 2008;63: 395-400.

2. Hauser SL, Waubant E, Arnold DL, et al. B-cell depletion with rituximab in relapsingremitting multiple sclerosis. N Engl J Med 2008;358:676-688.

3. Kappos L, Li D, Calabresi PA, et al. Ocrelizumab in relapsing-remitting multiple sclerosis: a phase 2, randomised, placebo-controlled, multicentre trial. Lancet 2011, 378:1779-1787.

4. Hauser SL, Bar-Or A, Comi G, et al. Ocrelizumab versus interferon beta-1a in relapsing multiple sclerosis. N Engl J Med 2017;376:221-234.

5. Bleeker WK, Munk ME, Mackus WJ, et al. Estimation of dose requirements for sustained in vivo activity of a therapeutic human anti-CD20 antibody. Br J Haematol 2008;140:303-312.

6. Teeling JL, Mackus WJ, Wiegman LJ, et al. The biological activity of human CD20 monoclonal antibodies is linked to unique epitopes on CD20. J Immunol 2006;177: 362-371.

7. Sorensen PS, Lisby S, Grove R, et al. Safety and efficacy of ofatumumab in relapsing remitting multiple sclerosis: a phase 2 study. Neurology 2014;82:573-581.

8. Kurrasch R, Brown JC, Chu M, et al. Subcutaneously administered ofatumumab in rheumatoid arthritis: a phase I/II study of safety, tolerability, pharmacokinetics, and pharmacodynamics. J Rheumatol 2013;40:1089-1096.

9. Stecco A, Migazzo E, Saponaro A, et al. Gadolinium dose optimisation in patients with multiple sclerosis: intra- and inter-individual comparisons. Eur J Radiol 2006 $57: 37-42$.

10. Sorman MP, Bruzzi P, Rovaris M, et al. Modelling new enhancing MRI lesion counts in multiple sclerosis. Mult Scler 2001;7:298-304.

11. Genovese MC, Kaine JL, Lowenstein MB, et al. Ocrelizumab, a humanized anti-CD20 monoclonal antibody, in the treatment of patients with rheumatoid arthritis: a phase I/II randomized, blinded, placebo-controlled, dose-ranging study. Arthritis Rheum 2008;58:2652-2661.

12. Chan AC. B cell immunotherapy in autoimmunity: 2010 update. Mol Immunol 2011; 48:1344-1347.

13. Lehmann-Horn K, Kronsbein HC, Weber MS. Targeting B cells in the treatment of multiple sclerosis: recent advances and remaining challenges. Ther Adv Neurol Disord 2013;6:161-173.

14. Wierda WG, Kipps TJ, Mayer J, et al. Ofatumumab as single-agent CD20 immunotherapy in fludarabine-refractory chronic lymphocytic leukemia. J Clin Oncol 2010; 28:1749-1755.

15. Wierda WG, Padmanabhan S, Chan GW, Gupta IV, Lisby S, Osterborg A. Ofatumumab is active in patients with fludarabine-refractory CLL irrespective of prior rituximab: results from the phase 2 international study. Blood 2011;118:5126-5129.

16. Ostergaard M, Baslund B, Rigby W, et al. Ofatumumab, a human anti-CD20 monoclonal antibody, for treatment of rheumatoid arthritis with an inadequate response to one or more disease-modifying antirheumatic drugs: results of a randomized, double-blind, placebo-controlled, phase I/II study. Arthritis Rheum 2010;62:2227-2238.

17. Taylor PC, Quattrocchi E, Mallett S, Kurrasch R, Petersen J, Chang DJ. Ofatumumab, a fully human anti-CD20 monoclonal antibody, in biological-naive, rheumatoid arthritis patients with an inadequate response to methotrexate: a randomised, doubleblind, placebo-controlled clinical trial. Ann Rheum Dis 2011;70:2119-2125.

18. Teeling JL, French RR, Cragg MS, et al. Characterization of new human CD20 monoclonal antibodies with potent cytolytic activity against non-Hodgkin lymphomas. Blood 2004;104:1793-1800. 


\title{
Subcutaneous ofatumumab in patients with relapsing-remitting multiple sclerosis
}

\author{
The MIRROR study
}

Amit Bar-Or, MD, Richard A. Grove, MSc, Daren J. Austin, PhD, Jerry M. Tolson, PhD, Susan A. VanMeter, MD, Eric W. Lewis, MD, Frederick J. Derosier, DO, Monica C. Lopez, Sarah T. Kavanagh, MPH, Aaron E. Miller, MD, and Per S. Sorensen, MD
Correspondence

Dr. Bar-Or

amitbar@upenn.edu

Cite as: Neurology ${ }^{\circledR}$ 2018;90:e1805-e1814. doi:10.1212/WNL.0000000000005516

Trial registration number

ClinicalTrials.gov: NCT01457924.

\section{Study question}

What is the minimally effective dose of the anti-CD20 monoclonal antibody ofatumumab in patients with relapsing forms of multiple sclerosis (RMS)?

\section{Summary answer}

Although all subcutaneous doses of ofatumumab demonstrated efficacy, most robust effects were observed for cumulative doses $\geq 30$ $\mathrm{mg} / 12$ weeks, including doses that did not fully deplete circulating B cells.

\section{Classification of evidence \\ Class I.}

\section{What is known and what this paper adds}

Selectively targeting B-cells using anti-CD20 monoclonal antibodies is highly effective at limiting disease activity in patients with RMS. This study indicates that treatment with ofatumumab decreases the number of new lesions on gadolinium-enhanced MRI within 12 weeks of treatment initiation and may not require complete depletion of circulating B cells.

\section{Participants and setting}

This phase $2 \mathrm{~b}$, multicenter, randomized, double-blind, placebocontrolled study treated 231 patients with active RMS (mean age: $37.2 \pm 9.36$ years; mean disease duration: $4.38 \pm 5.53$ years), all of whom had Expanded Disability Status Scale (EDSS) scores $\leq 5.5$.

\section{Design, size, and duration}

During the first 24 weeks (treatment phase), eligible patients were randomized (2:1:1:1:2) to placebo or ofatumumab at doses of 3, 30, or $60 \mathrm{mg}$ every 12 weeks, or $60 \mathrm{mg}$ every 4 weeks, respectively. At week 12, all patients in the placebo group received a single $3 \mathrm{mg}$ ofatumumab dose. The treatment schedule of all groups originally randomized to receive ofatumumab was maintained weeks 12-24. Following completion of the treatment phase, patient safety and B-cell repletion were monitored during a 24-week follow-up phase. Beginning at week 48, individual patients whose $\mathrm{CD} 19^{+}$B-lymphocyte counts remained below the lower limit of normal and who had not started other treatment entered an individualized follow-up phase.
Table Baseline patient demographic characteristics (safety population) and disease history (mITT population)

\begin{tabular}{lllllll}
\hline $\begin{array}{l}\text { Disease } \\
\text { history (mITT } \\
\text { population), }\end{array}$ & $\mathbf{6 7}$ & $\mathbf{3 3}$ & $\mathbf{3 2}$ & $\mathbf{3 3}$ & $\mathbf{6 3}$ & $\mathbf{2 2 8}$ \\
\hline $\begin{array}{l}\text { Clinical } \\
\text { disease duration, } \\
\text { mean (SD), } \mathbf{y}\end{array}$ & $\begin{array}{l}3.92 \\
(5.293)\end{array}$ & $\begin{array}{l}3.90 \\
(6.193)\end{array}$ & $\begin{array}{l}6.10 \\
(6.032)\end{array}$ & $\begin{array}{l}3.59 \\
(4.407)\end{array}$ & $\begin{array}{l}4.68 \\
(5.641)\end{array}$ & $\begin{array}{l}4.38 \\
(5.530)\end{array}$ \\
\hline $\begin{array}{l}\text { Relapses } \\
\text { (last 12 mo), }\end{array}$ & 1.3 & 1.4 & 1.3 & 1.3 & 1.3 & 1.3 \\
mean (SD), & $(0.58)$ & $(0.61)$ & $(0.67)^{\mathrm{a}}$ & $(0.60)$ & $(0.70)$ & $(0.3)$ \\
\hline $\begin{array}{l}\text { Relapses } \\
\text { (last 24 mo), } \\
\text { mean (SD), }\end{array}$ & 1.8 & 1.7 & 1.9 & 1.9 & 1.8 & 1.8 \\
\hline
\end{tabular}

${ }^{a} n=31$.

\section{Primary outcomes}

The primary endpoint was defined as the cumulative number of new gadolinium-enhancing ( $\mathrm{GdE}$ ) brain lesions by week 12, the end of the placebo-controlled period.

\section{Main results and the role of chance}

The study reported a $65 \%$ reduction in the mean rate of cumulative new GdE lesions for all ofatumumab groups vs placebo between weeks $0-12$ (rate ratio: 0.35 ; 95\% confidence interval [CI]: 0.221, 0.548; $p<0.001$ ). Moreover, $\geq 90 \%$ suppression of new lesions was observed at all cumulative doses $\geq 30 \mathrm{mg}$ between weeks 4 and 12 (0.08 [0.044, 0.162$]$ to $0.10[0.056,0.187])$ in a post hoc analysis.

\section{Harms}

Adverse events (AEs) were largely mild-to-moderate in severity. Incidences of serious AEs (SAEs) were $3 \%,<1 \%, 4 \%$, and $<1 \%$ in weeks $0-12,12-24,24-48$, and the individualized follow-up phase, respectively.

\section{Bias, confounding, and other reasons for caution}

The use of a conditioning dose may have confounded the data.

\section{Generalizability to other populations}

The results may be generalizable to other treatment regimens, although further study is required.

\section{Study funding/potential competing interests}

This study was funded by GlaxoSmithKline. Go to Neurology.org/N for full disclosures.

A draft of the short-form article was written by D. Drobish, a writer with Editage, a division of Cactus Communications. The authors of the fulllength article and the journal editors edited and approved the final version. 


\section{Neurology}

Subcutaneous ofatumumab in patients with relapsing-remitting multiple sclerosis: The MIRROR study

Amit Bar-Or, Richard A. Grove, Daren J. Austin, et al.

Neurology 2018;90;e1805-e1814 Published Online before print April 25, 2018

DOI 10.1212/WNL.0000000000005516

This information is current as of April 25, 2018

Neurology ${ }^{\circledR}$ is the official journal of the American Academy of Neurology. Published continuously since 1951, it is now a weekly with 48 issues per year. Copyright $@ 2018$ The Author(s). Published by Wolters Kluwer Health, Inc. on behalf of the American Academy of Neurology.. All rights reserved. Print ISSN: 0028-3878. Online ISSN: 1526-632X.

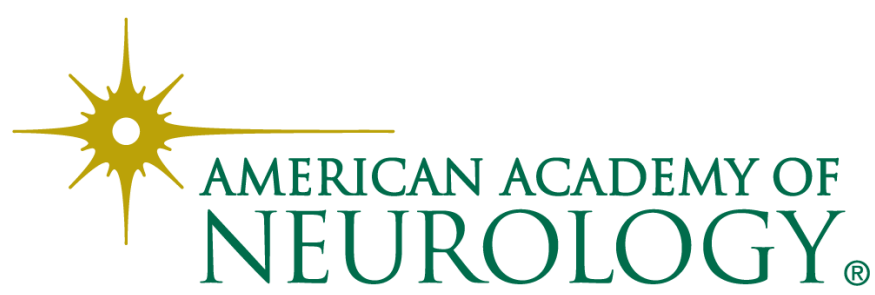




\section{Updated Information \& Services}

References

Citations

Subspecialty Collections

Errata

Permissions \& Licensing

Reprints including high resolution figures, can be found at: http://n.neurology.org/content/90/20/e1805.full

This article cites 18 articles, 7 of which you can access for free at: http://n.neurology.org/content/90/20/e1805.full\#ref-list-1

This article has been cited by 3 HighWire-hosted articles: http://n.neurology.org/content/90/20/e1805.full\#\#otherarticles

This article, along with others on similar topics, appears in the following collection(s):

Autoimmune diseases

http://n.neurology.org/cgi/collection/autoimmune_diseases Clinical trials Randomized controlled (CONSORT agreement) $\mathrm{http} / / /$ n.neurology.org/cgi/collection/clinical_trials_randomized_contro lled_consort_agreement

MRI

http://n.neurology.org/cgi/collection/mri

Multiple sclerosis

http://n.neurology.org/cgi/collection/multiple_sclerosis

An erratum has been published regarding this article. Please see next page or: /content/91/11/538.full.pdf

Information about reproducing this article in parts (figures,tables) or in its entirety can be found online at:

http://www.neurology.org/about/about_the_journal\#permissions

Information about ordering reprints can be found online:

http://n.neurology.org/subscribers/advertise

Neurology ${ }^{\circledR}$ is the official journal of the American Academy of Neurology. Published continuously since 1951, it is now a weekly with 48 issues per year. Copyright @ 2018 The Author(s). Published by Wolters Kluwer Health, Inc. on behalf of the American Academy of Neurology.. All rights reserved. Print ISSN: 0028-3878. Online ISSN: 1526-632X.

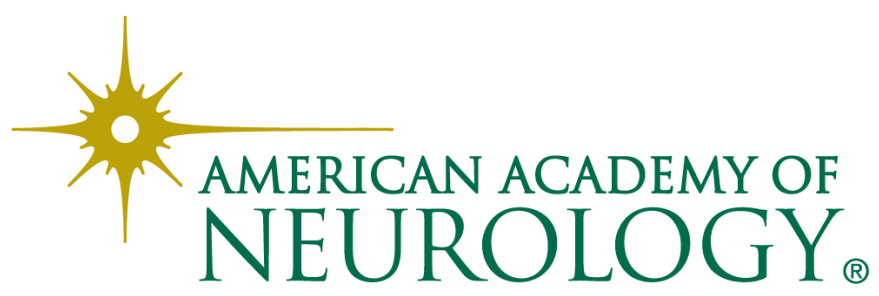




\title{
Disputes \& Debates: Editors' Choice
}

\author{
Steven Galetta, MD, FAAN, Section Editor
}

\section{Editors' note: An interdisciplinary response to contemporary concerns about brain death determination}

"An interdisciplinary response to contemporary concerns about brain death determination" generated several readers' responses. Commenting on the paper, Verheijde et al. argue that cardiopulmonary death is not the equivalent to brain death and add that public trust in brain death requires that there be zero false-positive determinations of death. Dr. Sethi suggests that lawsuits related to brain death may be linked more to breakdowns in communication between the medical teams and patient families rather than validity of determination of death by neurologic criteria. Machado et al. suggest that ancillary tests should have a decisive role in helping to delineate the brain death concept since clinical evaluation might have pitfalls. Finally, Dr. Shabtai feels that it is an error to frame the debate as one of religious or moral beliefs vs science, and suggests continued discussion, including broad public debate. Authors Lewis et al. defend their article citing several prominent American medical societies who support that brain death is equivalent to cardiopulmonary death. They add that when the American Academy of Neurology guidelines are appropriately applied, there are zero false-positive determinations of death. They suggest including a social worker, psychologist, palliative care specialist, chaplain, and religious figure in conversations about brain death. They explain that ancillary testing is recommended to assess for lack of intracranial blood flow or cerebral activity if a clinical evaluation cannot be completed, but the gold standard for determination of brain death is a full clinical evaluation. Further, they add that ancillary testing is imperfect and there are risks when performing testing and interpreting the results. Finally, they remind the reader that the 1981 President's Commission determined that death should be defined based on complete loss of function of the brain or the heart and lungs, but deferred to the medical community to establish the specific criteria for determination of death. They stress that it is the medical community's responsibility to ensure that it is clear what constitutes "accepted medical standards" for determination of death and that these criteria are adhered to consistently and accurately.

Chafic Karam, MD, and Steven Galetta, MD

Neurology ${ }^{\circledR}$ 2018;91:533. doi:10.1212/WNL.0000000000006149

\section{Reader response: An interdisciplinary response to contemporary concerns about brain death determination}

Joseph L. Verheijde (Scottsdale), Mohamed Y. Rady (Phoenix), and Michael Potts (Fayetteville) Neurology ${ }^{\circledR}$ 2018;91:533-534. doi:10.1212/WNL.0000000000006150

We disagree with redefining death "based on loss of clinical function of the heart and lungs or the brain," because it deviates from the legal definition of irreversible cessation of cardiorespiratory function or of all functions of the brain, including the brainstem. The latter was intended to protect the general public from injury and harm due to incorrect death declaration. The contemporary clinical criteria have been challenged on scientific, philosophical, legal, and religious grounds. ${ }^{2-4}$ Lewis et al. reduce this opposition to "moral or religious beliefs, hope that a patient will recover, or a lack of acceptance that a determination of brain death is the legal equivalent of 
a determination of cardiopulmonary death."1 Religious objection stems from incongruence with the hylomorphic Thomistic concept of death (body-soul connection) underlying Abrahamic faith traditions. The "lack of acceptance" originates from low-level supporting scientific evidence and absence of a coherent philosophical rationale. ${ }^{4}$ Furthermore, American Academy of Neurology practice guidelines are more consistent with the brainstem rather than the whole-brain death definition.

Public trust depends on determining death using a criterion with zero false-positives. Although some have advocated silencing opposing views and ending dissension on brain death, ${ }^{5}$ we welcome a broad public debate on the basis of contemporary (neuro)science advances, philosophical reasoning, and anthropologic and theologic considerations.

1. Lewis A, Bernat JL, Blosser S, et al. An interdisciplinary response to contemporary concerns about brain death determination. Neurology 2018;90:423-426.

2. Joffe AR. Brain death is not death: a critique of the concept, criterion, and tests of brain death. Rev Neurosci 2009;20:187-198.

3. Yanke G, Rady MY, Verheijde JL. When brain death belies belief. J Relig Health 2016;55:2199-2213.

4. Shewmon DA. False-positive diagnosis of brain death following the pediatric guidelines: case report and discussion. J Child Neurol 2017;32:1104-1117.

5. Dubois JM. The ethics of creating and responding to doubts about death criteria. J Med Philos 2010;35:365-380.

\section{Reader response: An interdisciplinary response to contemporary concerns about brain death determination}

Nitin K. Sethi (New York)

Neurology ${ }^{\circledR} 2018 ; 91: 534$. doi:10.1212/WNL.0000000000006151

I read with interest the response of the interdisciplinary committee to contemporary concerns about brain death determination. ${ }^{1}$ A deeper analysis of the lawsuits related to brain death determination reveals that, in a significant number, the issue was not the validity of determination of death by neurologic criteria or the inconsistency with the 2010 American Academy of Neurology practice guideline prevalent among different institutions in the United States and abroad; rather, the crux of the problem lies in the manner death by neurologic criteria was conveyed to the family by the physician.

While patients who meet either cardiopulmonary or brain death criteria are in both cases legally dead, it is far easier and final for the grieving family to accept that their loved one is dead when the heart has stopped beating than to be told that the brain has been irreversibly damaged and that the "death of the brain" is equivalent to the "death of the person as a whole."

"They say you die twice. One time when you stop breathing and a second time, a bit later on, when somebody says your name for the last time" is a quote attributed to Banksy. A large segment of the public still feels that one dies twice. Once when the heart stops and once when the brain stops. The first step to dispelling this myth is to stop using terms such as "brain death" or "death by neurologic criteria" when talking to a patient's family. "Death is death no matter whether the heart dies or the brain dies" is the message we need to get out.

1. Lewis A, Bernat JL, Blosser S, et al. An interdisciplinary response to contemporary concerns about brain death determination. Neurology 2018;90:423-426.

Copyright @ 2018 American Academy of Neurology

Author disclosures are available upon request (journal@neurology.org). 


\section{Reader response: An interdisciplinary response to contemporary concerns about brain death determination}

Calixto Machado, Mario Estevez (Havana), Phillip A. DeFina (Flanders), and Gerry Leisman (Haifa) Neurology ${ }^{\circledR} 2018 ; 91: 535$. doi:10.1212/WNL.0000000000006152

We read with interest the Contemporary Issues by Lewis et al. ${ }^{1}$ Previously, Dr. Bernat defended the whole-brain concept of brain death (BD), ${ }^{2}$ and the US President's Commission recommended its adoption by all US states. ${ }^{3}$ In 2015 , Wijdicks stated, "the irreversible absence of functions of the brainstem is the necessary and sufficient component of brain death." ${ }^{4}$ This view fully pertains to brainstem death, and not to the whole-brain criterion. ${ }^{5}$ The American Academy of Neurology summit concluded that "BD is defined by irreversible loss of consciousness and brainstem function," according to the whole-brain criterion. ${ }^{1}$

Well-designed surveys have shown discrepancies with the American Academy of Neurology guidelines on the use of ancillary tests. ${ }^{1,5}$ ECG monitoring is routinely used by physicians to diagnose a cardiac arrest. Patients' relatives more easily accept death when an ECG isoelectric line is observed in bedside monitors. There is no perfect confirmatory test, as clinical evaluation might have pitfalls. Ancillary tests should have a decisive role in helping to delineate the BD concept, as they have for outlining the cardiorespiratory view of death.

Is there a diagnosis of any disease in which a confirmatory test is not used? BD determination is the most challenging diagnosis. This might significantly reduce institutional protocol divergences in $\mathrm{BD}$ diagnosis. ${ }^{5}$

1. Lewis A, Bernat JL, Blosser S, et al. An interdisciplinary response to contemporary concerns about brain death determination. Neurology 2018;90:423-426.

2. Bernat JL. A defense of the whole-brain concept of death. Hastings Cent Rep 1998;28:14-23.

3. DigitalGeorgetown. Defining death: medical, legal and ethical issues in the determination of death [online]. Available at: hdl.handle.net/ 10822/559345. Accessed February 10, 2018.

4. Wijdicks EFC. The clinical determination of brain death: rational and reliable. Semin Neurol 2015;35:103-104.

5. Machado C, Estevez M, DeFina PA, et al. A reason for care in the clinical evaluation of function on the spectrum of consciousness. Funct Neurol Rehab Ergon (in press 2017).

\section{Reader response: An interdisciplinary response to contemporary concerns about brain death determination}

David Y. Shabtai (Boca Raton)

Neurology ${ }^{\circledR}$ 2018;91:535-536. doi:10.1212/01.wnl.0000544244.66565.8d

It is reassuring that questions surrounding the proper diagnosis of brain death are continuously being debated. ${ }^{1}$ However, while Lewis et al. acknowledge the existence of dissent regarding accepting brain death as the death of the individual, they frame the debate as one of beliefs vs science. This is an error.

The question of defining death is not one that lends itself to assertions by medical associations or physicians. Science and medicine are disciplines of facts and numbers, answering questions that ask what or how, but not questions of why. Indeed, assessing whether the criteria for death have been met requires precise medical determination. It necessitates expertise and precision, evaluating advancing technologies, and diagnostic acumen to evaluate specific physiologic parameters.

However, establishing those very criteria are questions of values and ethics. Selecting particular physiologic parameters for death requires assessing the values, ethics, and morals behind these 
decisions. ${ }^{2}$ These are not questions of science, but rather of philosophy and ethics. These are not questions to which additional scientific data are relevant, but must reflect the values and ethics of society.

Continued discussion—including broad public debate—should not only be welcome, but is necessary. Steering this discourse toward medical associations assumes that they accurately and effectively represent the values of society—an assertion that many would not quickly accept.

1. Lewis A, Bernat JL, Blosser S, et al. An interdisciplinary response to contemporary concerns about brain death determination. Neurology 2018;90:423-426.

2. Veatch RM. Transplantation Ethics. Washington: Georgetown University Press; 2000.

Copyright (c) 2018 American Academy of Neurology

\title{
Author response: An interdisciplinary response to contemporary concerns about brain death determination
}

\author{
Ariane Lewis (New York), James L. Bernat (Lebanon), Sandralee Blosser (Pittsburgh), \\ Richard J. Bonnie (Charlottesville), Leon G. Epstein (Chicago), John Hutchins (Minneapolis), \\ Matthew P. Kirschen (Philadelphia), Michael Rubin (Dallas), James A. Russell (Burlington), \\ Justin A. Sattin (Madison), Eelco F.M. Wijdicks (Rochester), and David M. Greer (Boston) \\ Neurology ${ }^{\circledR}$ 2018;91:536-538. doi:10.1212/WNL.0000000000006154
}

We appreciate the interest and comments of Verheijde et al., Dr. Sethi, Machado et al., and Dr. Shabtai.

We acknowledge that, as evidenced by the comment of Verheijde et al., some people, including physicians, do not believe that brain death is equivalent to cardiopulmonary death. Nonetheless, our multidisciplinary statement equating the two is supported by prominent American medical societies including the American Academy of Neurology, American Academy of Pediatrics, American College of Chest Physicians, American College of Radiology, American Neurological Association, American Society of Neuroradiology, Child Neurology Society, and Neurocritical Care Society. ${ }^{1}$ Of course, we welcome continued discussion on this topic, particularly if relevant scientific data emerge.

We heartily agree with Verheijde et al. that public trust in brain death requires that there be zero false-positive determinations of death. Review of the literature from 1996 to 2009 demonstrated that when the American Academy of Neurology guidelines were appropriately applied, there were zero false-positive determinations of death. ${ }^{2}$ However, inconsistent adherence to the guidelines can lead to false-positive determinations. We are working to avoid this by (1) promoting educational initiatives and brain death credentialing programs to ensure physicians performing evaluations for brain death determination are knowledgeable about the guidelines and comply with them, and (2) advocating for regulatory oversight to ensure determinations are performed according to the guidelines. Any alleged false-positive determination requires careful study.

To respond to Dr. Sethi's thoughtful comments: we believe that the triggers for the recent lawsuits related to brain death are multifactorial, but we agree that it is possible that breakdowns in communication between the medical teams and patient families had a role. Educating families about brain death can be challenging. It is important for physicians to bear in mind that religious formulations of death vary and that the public's perception of brain death is often based on misinformation published in the media and misrepresentations depicted in television and film. ${ }^{3-5}$ It is imperative that physicians who are involved in brain death determination be 
adept at patiently explaining the concept of brain death and its implications while demonstrating cultural competence, compassion, and empathy for families. Discussions about brain death may precipitate a deluge of emotions including anger, fear, depression, distrust, and even guilt. As a result, consideration should be given to including a social worker, psychologist, palliative care specialist, chaplain, and/or religious figure in conversations about brain death. Recommendations by Lewis et al. $^{6}$ for pediatric intensivists on communicating with families about brain death are universally applicable and should be included in brain death determination training sessions.

In regard to the concern by Machado et al. of protocol divergence, the legal and medical standards for determination of death by neurologic criteria in patients of all ages in the United States require irreversible cessation of all functions of the whole brain, including the brainstem. ${ }^{2,7,8}$ The guidelines for determination of brain death in both pediatric and adult patients define death based on clinical criteria. Ancillary testing is recommended to assess for lack of intracranial blood flow or cerebral activity if a clinical evaluation cannot be completed, but the gold standard for determination of brain death is a full clinical evaluation. ${ }^{2,8}$ However, we agree with Machado et al. that the clinical evaluation can have pitfalls. The solution to this is not mandating ancillary testing, though. Ancillary testing is imperfect and there are risks both when performing testing and interpreting the results. ${ }^{9}$ Despite this, some institutions require ancillary testing. ${ }^{10}$ To address these issues and ensure brain death determinations are consistent and accurate, we aim to (1) advocate for uniform institutional policies throughout the United States by implementing regulatory oversight, and (2) develop educational initiatives and credentialing programs.

We agree with Dr. Shabtai that the task of defining death requires input from specialists in a diverse range of fields. Accordingly, in 1981, the President's Commission for the Study of Ethical Problems in Medicine and Biomedical and Behavioral Research addressed this topic with emphasis on the question of whether brain death should be incorporated into the societal definition of death. ${ }^{11}$ This committee was composed of experts in bioethics, epidemiology, health economics, law, medicine, nursing, philosophy, public health, research science, and sociology and sought counsel from the American Bar Association, the American Medical Association, the National Conference of Commissioners on Uniform State Laws, and religious officials. ${ }^{11}$ The President's Commission determined that death should be defined based on complete loss of function of the brain (including the brainstem) or the heart and lungs, but deferred to the medical community to establish the specific criteria for determination of death. All 50 states adopted the definition of death the President's Commission created, or a variation thereof. ${ }^{12}$ As a result, it is the medical community's responsibility to ensure that it is clear what constitutes "accepted medical standards" for determination of death and that these criteria are adhered to consistently and accurately. In addition, we would argue Dr. Shabtai's implication that medical societies are epistemologically confined to the scientific method given that physicians, such as Aristotle and Maimonides, have always been key contributors to the philosophical discourse of medical ethics.

1. Lewis A, Bernat JL, Blosser S, et al. An interdisciplinary response to contemporary concerns about brain death determination. Neurology 2018;90:423-426.

2. Wijdicks EFM, Varelas PN, Gronseth GS, Greer DM. Evidence-based guideline update: determining brain death in adults: report of the Quality Standards Subcommittee of the American Academy of Neurology. Neurology 2010;74:1911-1918.

3. Lewis A, Weaver J, Caplan A. Portrayal of brain death in film and television. Am J Transpl 2017;17:761-769.

4. Lewis A, Lord AS, Czeisler BM, Caplan A. Public education and misinformation on brain death in mainstream media. Clin Transpl 2016;30:1082-1089.

5. Setta SM, Shemie SD. An explanation and analysis of how world religions formulate their ethical decisions on withdrawing treatment and determining death. Philos Ethics Humanit Med 2015;10:6.

6. Lewis A, Adams N, Chopra A, Kirschen MP. Organ support after death by neurologic criteria in pediatric patients. Crit Care Med 2017; 45:e916-e924.

7. President's Commission for the Study of Ethical Problems in Medicine and Biomedical and Behavioral Research. Defining Death: Medical, Legal and Ethical Issues in the Determination of Death. Washington, DC: US Government Printing Office; 1981. 

the determination of brain death in infants and children: an update of the 1987 task force recommendations_executive summary. Ann Neurol 2012;71:573-585.

9. Wijdicks EFM. The case against confirmatory tests for determining brain death in adults. Neurology 2010;75:77-83.

10. Greer DM, Wang HH, Robinson JD, Varelas PN, Henderson GV, Wijdicks EFM. Variability of brain death policies in the United States. JAMA Neurol 2016;73:213-218.

11. DigitalGeorgetown. Defining death: medical, legal and ethical issues in the determination of death[online]. Available at: hdl.handle.net/ 10822/559345. Accessed February 10, 2018.

12. Lewis A, Cahn-Fuller K, Caplan A. Shouldn't dead be dead? The search for a uniform definition of death. J Law Med Ethics 2017;45: $112-128$.

Copyright (c) 2018 American Academy of Neurology

CORRECTION

\section{Subcutaneous ofatumumab in patients with relapsing-remitting multiple sclerosis}

The MIRROR study

Neurology ${ }^{\circledR} 2018 ; 91: 538$. doi:10.1212/WNL.0000000000005929

In the article "Subcutaneous ofatumumab in patients with relapsing-remitting multiple sclerosis: The MIRROR study" by A. Bar-Or et al., ${ }^{1}$ there is an error in the Disclosure section. The original disclosure statement erroneously indicated Dr. Bar-Or was an employee and stockholder in GlaxoSmithKline. However, it should have read "A. Bar-Or has received consulting fees from GlaxoSmithKline.” All other disclosures are correct as originally published. The authors regret the error.

\section{Reference}

1. Bar-Or A, Grove RA, Austin DJ, et al. Subcutaneous ofatumumab in patients with relapsing-remitting multiple sclerosis: the MIRROR study. Neurology 2018;90:e1805-e1814 